\title{
Reliability Evaluation of Roy Billinton Test System
}

\author{
P.Sangeetha ${ }^{1}$, S.Sowjanya ${ }^{2}$ \\ ${ }^{1}$ Assistant Professor, Department of Electrical and Electronics Engineering, JNTUH College of Engineering, \\ Jagtial, Telangana, India, sangeetha813@gmail.com \\ ${ }^{2}$ Currently Pursuing M.Tech, Department of Electrical and Electronics Engineering, JNTUH College of \\ Engineering, Jagtial, Telangana, India, sowji342@gmail.com
}

\begin{abstract}
Reliability play's a major role at power system planning and operation. Reliability means continuous power supply to end users without outages. So in order to study reliability of any system we consider two methods which are Analytical and Monte-Carlo simulation. Analytical methods are mathematical models which gives numerical calculations for simple systems. Monte Carlo Simulation is a proposed method which is used in case of complex systems. RBTS BUS-2 test system is used as case study with DG's at different locations and without DG's to evaluate fundamental reliability indices, customer oriented indices SAIFI, SAIDI, CAIDI .Cost/worth indices such as EENS, ECOST and IEAR are calculated and compared by both Analytical and Monte-Carlo simulation. In Monte-Carlo time sequential technics indices are calculated by using random number generators with UP and DOWN states times of system elements.
\end{abstract}

Key words: Analytical Techniques, Cost/Worth Indices, Monte-Carlo Time Sequential Techniques, Reliability Indices.

\section{INTRODUCTION}

A basic function of electrical power system is to supply reliable power with high system security and system adequacy. A modern power system is a complex and very large, to know the reliability assessment of entire system simply, it is divided into subsystems which can be analyzed and estimated separately. They are generation system, composite generation and transmission system, and distribution system. Here three hierarchical levels are developed to identify and grouping those functional zones.

- At Hierarchical level 1 only generation system reliability is considered and the transmission and distribution system are considered fully reliable.

- At Hierarchical level 2 both generation and transmission is considered and it is also known as composite power system analysis.
- At Hierarchical level 3 entire system is analyzed .In particular distribution system along with the previous levels are considered.

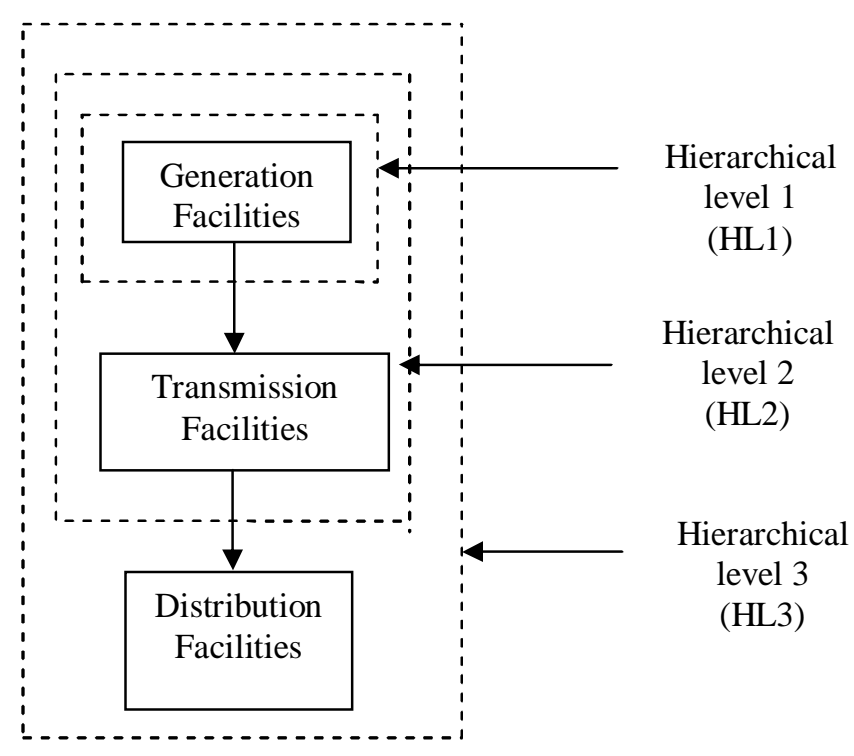

Figure 1: Hierarchical Levels

\section{OBJECTIVE}

Power system is a complex network which consists of different major type's generation, transmission and distribution, so there may be outages due to various types of faults, maintenance, switches replacement. It is a measure of increase of availability and decrease of unavailability of the system, so that outages reduced and hence customer gets reduced outage power. In this paper RBTS BUS-2 distribution system network is used to test the proposed method Monte-Carlo simulation.

\subsection{Literature Review}

RBTS BUS-2 (Roy Billinton Test System Bus-2) failure time, repair time and sectional lengths has [7] taken to analyze reliability indices, Analytical methods for the three Hierarchical levels has seen in [1], [3] has basic methods for the distribution system Cost/Worth indices. [2] and [5] 
describes Monte-Carlo simulation methods for distribution system and composite system, whereas [4] has explained simulation methods for complex systems.

Various probability distribution methods and Analytical methods [6] has explained, Variation of different reliability indices according to different customers like residential, commercial and industrial has seen in [8]. In [9] cost/worth indices CCDF, SCDF, ECOST and IEAR evaluated for the complex system like RBTS BUS-2.

\section{RELIABILITY INDICES}

A radial distribution system consists of various components which include tie switches, circuit breakers, fuses, isolators, transformers etc. Each component which present at radial distribution system will have average failure rate of each component ' $\lambda$ ', average repair time of each component ' $r$ ' and annual outage time ' $U$ ' are given as

$\lambda_{s}=\sum \lambda_{i}$

$U_{s}=\sum \lambda_{i} r_{i}$

$r_{s}=U_{s} / \lambda_{s}=\sum \lambda_{i} r_{i} / \sum \lambda_{i}$

By using this fundamental reliability indices $\lambda, r, u$ we find system reliability indices.

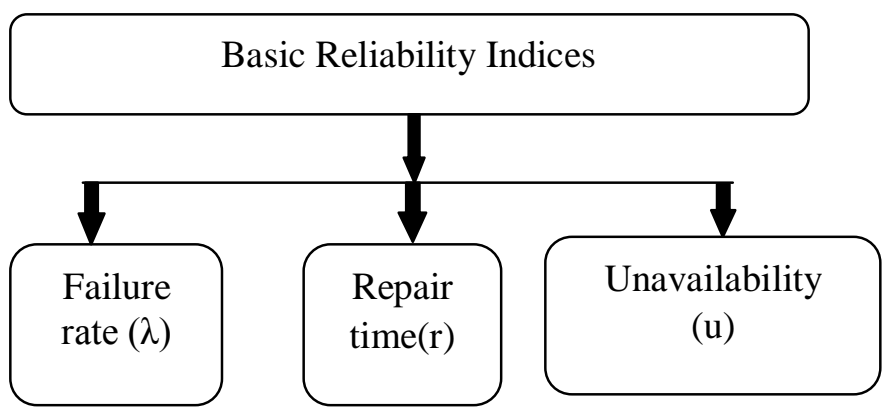

Figure 2: Basic Reliability Indices

\subsection{Customer-orientated indices}

\subsubsection{System Average Interruption Frequency Index (SAIFI)}

$$
\mathrm{SAIFI}=\frac{\text { total number ofcustomer interruptions }}{\text { total no of customers served }}=\frac{\sum \lambda j N j}{\sum \mathrm{Nj}}
$$

Where, $\lambda_{j}$ is the average failure rate of $j_{t h}$ load.

$\mathrm{N}_{\mathrm{j}}$ is the total number of customers of $j_{t h}$ load.

\subsubsection{System Average Interruption Duration Index (SAID)}

\footnotetext{
SAIDI $=\frac{\text { total number of customer interruption duration }}{\text { total number of customers served }}=$ $\frac{\sum U j N j}{\sum N j}$

Where, $U_{j}$ is the annual outage time
}

$N_{j}$ is total number of customers of $j_{t h}$ load point

\subsubsection{Customer Average Interruption Duration Index}

(CAIDI)

$\mathrm{CAIDI}=\frac{\text { sum } \text { of customer interruption durations }}{\text { total number of customer interruption }}=\frac{\sum U j N j}{\sum \lambda j \mathrm{Nj}}$

Where, $\lambda_{j}$ is the failure rate.

$U_{j}$ is the annual outage time.

$N_{j}$ is the number of customers.

3.1.4 Customer Average Interruption Frequency Index (CAIFI)

$$
\text { CAIFI }=\frac{\text { total number of customer interruptions }}{\text { total number of customers affected }}
$$

\subsubsection{Average Service Availability Index (ASAI)}

ASAI $=\quad \frac{\text { Customer hoursofavailableservice }}{\text { Customer hoursdemand }}$
$\frac{\sum N j * 8760-\sum U j N j}{\sum N j * 8760}$
Where, $U_{j}$ is the annual outage time.
$N_{j}$ is the total number of customers.

\subsubsection{Average Service Unavailability Index (ASUI)}

$$
\text { ASUI }=\frac{\text { Customer hours of unavailability service }}{\text { Customer hours demanded }}=\frac{\sum U j N j}{\sum N j * 8760}
$$

Where 8760 is the number of hours in a calendar year.

\subsection{Energy -orientated indices}

For energy-orientated indices, at each load point bus bar one of the important parameter is average load demand.

\subsubsection{Energy Not Supplied Index (ENS)}

$\mathbf{E N S}=\mathbf{L}_{\mathbf{a}} \lambda_{\mathbf{j}} \mathbf{r}_{\mathbf{j}}$

Where,

$\mathrm{L}_{\mathrm{a}}$ is the average load demand

$\lambda_{\mathrm{j}}$ is the failure rate of $\mathrm{j}_{\mathrm{th}}$ load

$r_{j}$ is the repair time of $j_{t h}$ load

\subsubsection{Average Energy Not Supplied (AENS)}

$$
\text { AENS }=\frac{\text { Total energy not supplied }}{\text { Total number of customers served }}=\sum \mathrm{L}_{\mathrm{a}} \lambda_{\mathrm{j}} \mathrm{r}_{\mathrm{j}} / \sum \mathrm{N}_{\mathrm{j}}
$$

Where,

$\mathrm{N}_{\mathrm{j}}$ is the number of customers connected at $\mathrm{j}_{\mathrm{th}}$ load. 


\section{PROPOSED METHOD}

\subsection{Analytical Technique}

Reliability assessment of radial distribution network can be studied by using one of the method is analytical method. It is a mathematical model by considering equations. This method is applied to the RBTS BUS-2 to evaluate the reliability of the power system.

This technique gives the following results as follows, Fundamental reliability indices- $\lambda, r, u$ Customer Oriented indices- SAIFI, SAIDI, CAIDI Cost/Worth indices -EENS, ECOST, IEAR

Actually, fundamental reliability indices of any load point ' $\mathrm{j}$ ' as follows

$\lambda j=\lambda_{T}+\lambda_{L S}+\lambda_{M S}+\ldots \ldots \ldots \ldots \ldots \ldots \ldots \lambda_{M S j}(f / y e a r)$

Where,

$\lambda_{\mathrm{T}}=$ Average failure rate at transformer.

$\lambda_{\mathrm{LS}}=$ Average failure rate at lateral section

$\lambda_{\mathrm{MS}}=$ Average failure rate at main section.

$U_{j}=\lambda_{T} r_{T}+\lambda_{L S} r_{L S}+\lambda_{M S} r_{M S}+\ldots \ldots \ldots \ldots \ldots \lambda_{M S j} r_{M S j}(h / Y r)$

By using fundamental reliability indices, system reliability indices SAIFI, SAIDI, CAIDI are evaluated.

By using Sector Customer Damage Function (SCDF), we find Customer Damage Function (CDF) at every type of customer at each load point.

$C_{j}=f\left(r_{j}\right)$

$\operatorname{SCDF}(t)=1 / m \sum_{j=1}^{m} \operatorname{oci}(t)($ Baht/event $)$

$\operatorname{CCDF}(t)=\sum_{\mathrm{p}=1}^{\mathrm{p}} \operatorname{SCDF}(\mathrm{t}) * \mathrm{~W}_{(\text {Baht/event })}$

Where,

$\mathrm{OC}_{\mathrm{j}}(\mathrm{t})=$ Outage cost for load point ' $\mathrm{J}$ ' at outage rate at ' $\mathrm{t}$ '.

$\mathrm{m}=$ in a sector number of respondents.

$\mathrm{W}_{\mathrm{p}}=$ Weighting factor of each sector.

$\mathrm{P}=\mathrm{No}$ of sectors.

Cost/worth indices can be evaluated by considering each load point indices $\lambda, \mathrm{r}, \mathrm{u}$ Customer damage function and average load demand.

$E E N S_{j}=L_{j} r_{j} \lambda_{j}$

$E C O S T=C_{j} L_{j} \lambda_{j}$

$I E A R_{i j}=E C O S T_{j} / E E N S_{j}=C_{j} / r_{j}$

Where,

EENS is Expected Energy Not Supplied of $j_{t h}$ load.
ECOST is Expected Customer outage Cost of $j_{\text {th }}$ load. IEAR is Interruption Energy Assessment Rate of $\mathrm{j}_{\mathrm{th}}$ load.

\subsection{Time Sequential Technique}

Simulation procedure is one of the method by which we can find reliability evaluation of distribution networks. It is used mostly in place of complex networks and the solution obtained is finite value. It is used mostly in place of generation systems, transmission systems and distribution systems.

In time sequential simulation technique one the important parameter to evaluate reliability of system is operation modes of elements, which can be studied by state model as shown in the figure 3 .

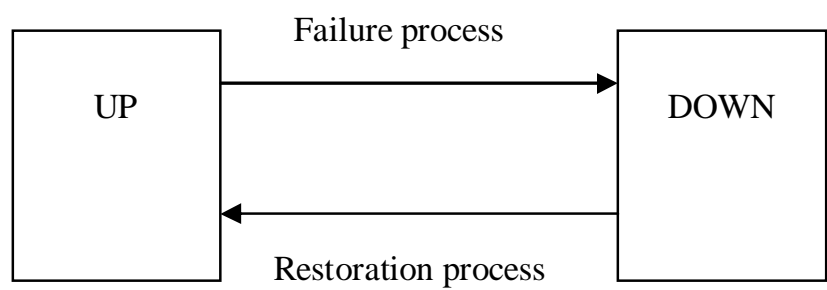

Figure 3: State Space Diagram

Where up state to down state is called failure process and down-state to up-state is called restoration process

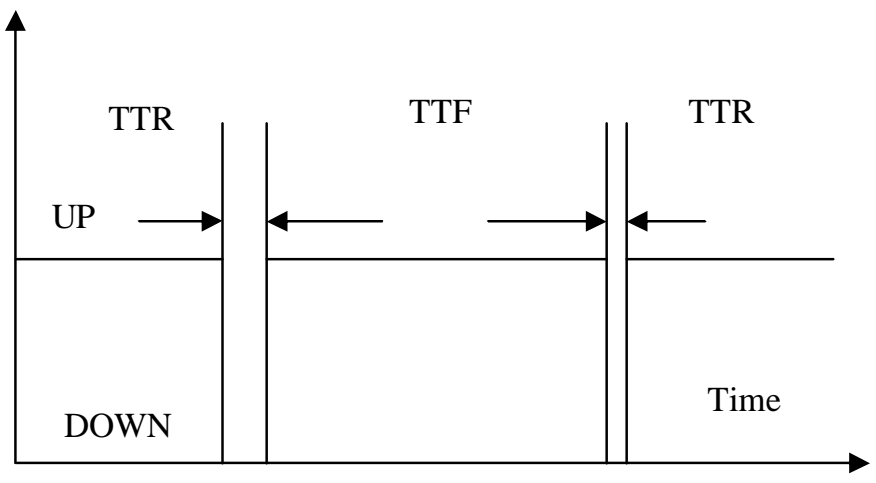

Figure 4: Time History of Operating and Restoration Process

TTF, TTR are time domain parameters which represents the failure and restoration process.

Table 1: Additional DG Data

\begin{tabular}{|c|c|c|c|}
\hline Type of DG & $\begin{array}{c}\text { Failure } \\
\text { rate(f/yr) }\end{array}$ & $\begin{array}{c}\text { Repair } \\
\text { time }(\mathrm{hr})\end{array}$ & Switching time \\
\hline $\begin{array}{c}500 \mathrm{kw} \text { Diesel } \\
\text { generator } \\
\text { (DG) }\end{array}$ & 0.87 & 3.9 & 1 \\
\hline
\end{tabular}




\subsection{Flow Chart for Analytical Method}

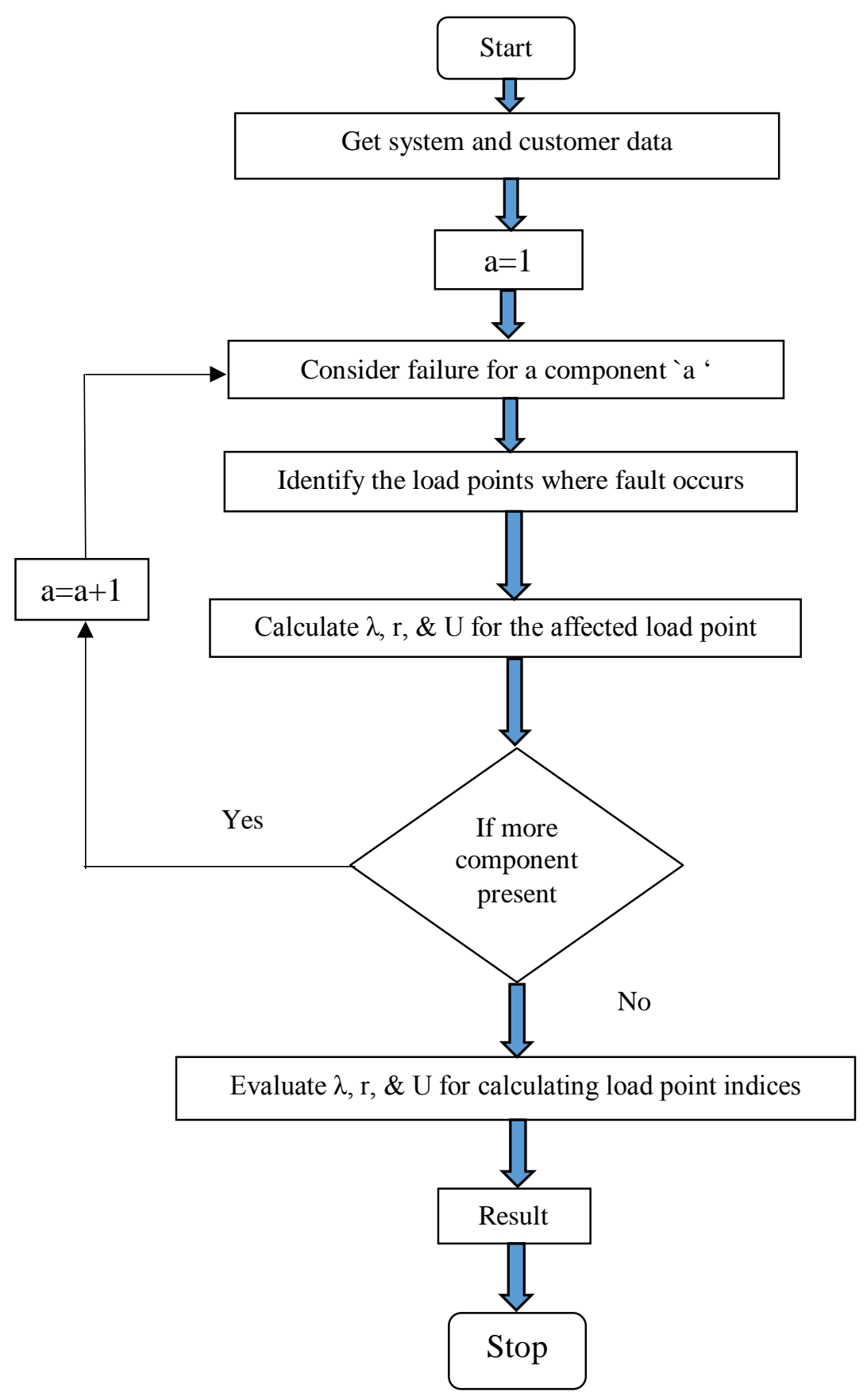

Figure 5: Flow Chart for Analytical Method

Time to Failure (TTF)

$T T F=-1 / \lambda \ln \left(U_{1}\right)$

Time to Repair (TTR)

$T T R=-1 / \mu \ln \left(U_{2}\right)$

Where $\mathrm{U}_{1}$ and $\mathrm{U}_{2}$ are two random numbers. 


\subsection{Flow Chart for Monte-Carlo Method}

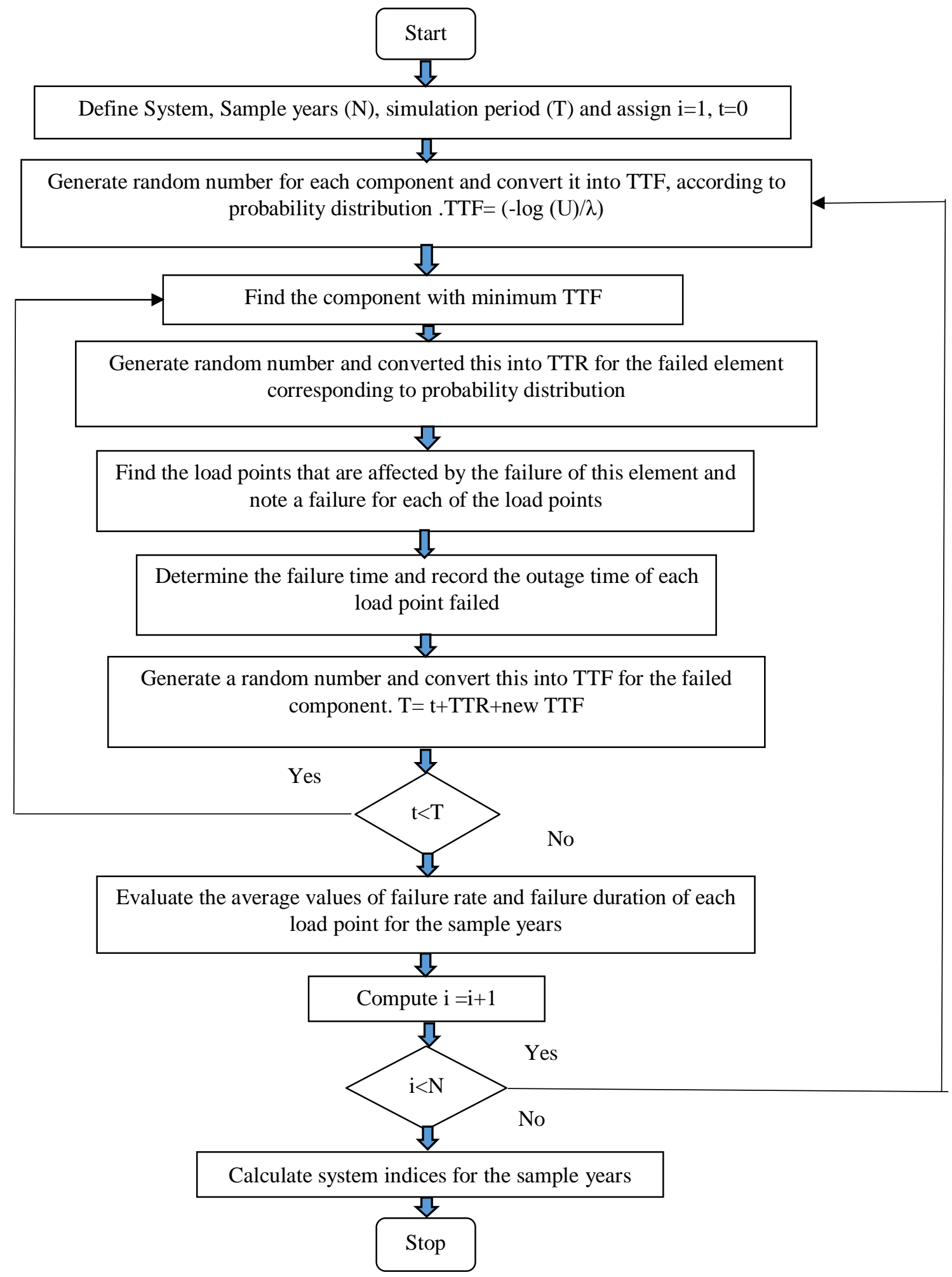

Figure 6: Flow Chart for Monte-Carlo Method 


\section{CASE STUDY}

The proposed method is applied to RBTS BUS-2 with and without Diesel Generator (DG), it consists of mainly four feeders F1, F2, F3, F4 consists of 22 load points with different types of customers connected to $33 / 11 \mathrm{kv}$ distribution network has 36 sectional lengths, Transformers, Circuit breakers. Different components of the system has different failure rate, repair times and switching times. Step by step procedure for Monte-Carlo and Analytical methods is shown in the above flow charts see figures 5 and 6.

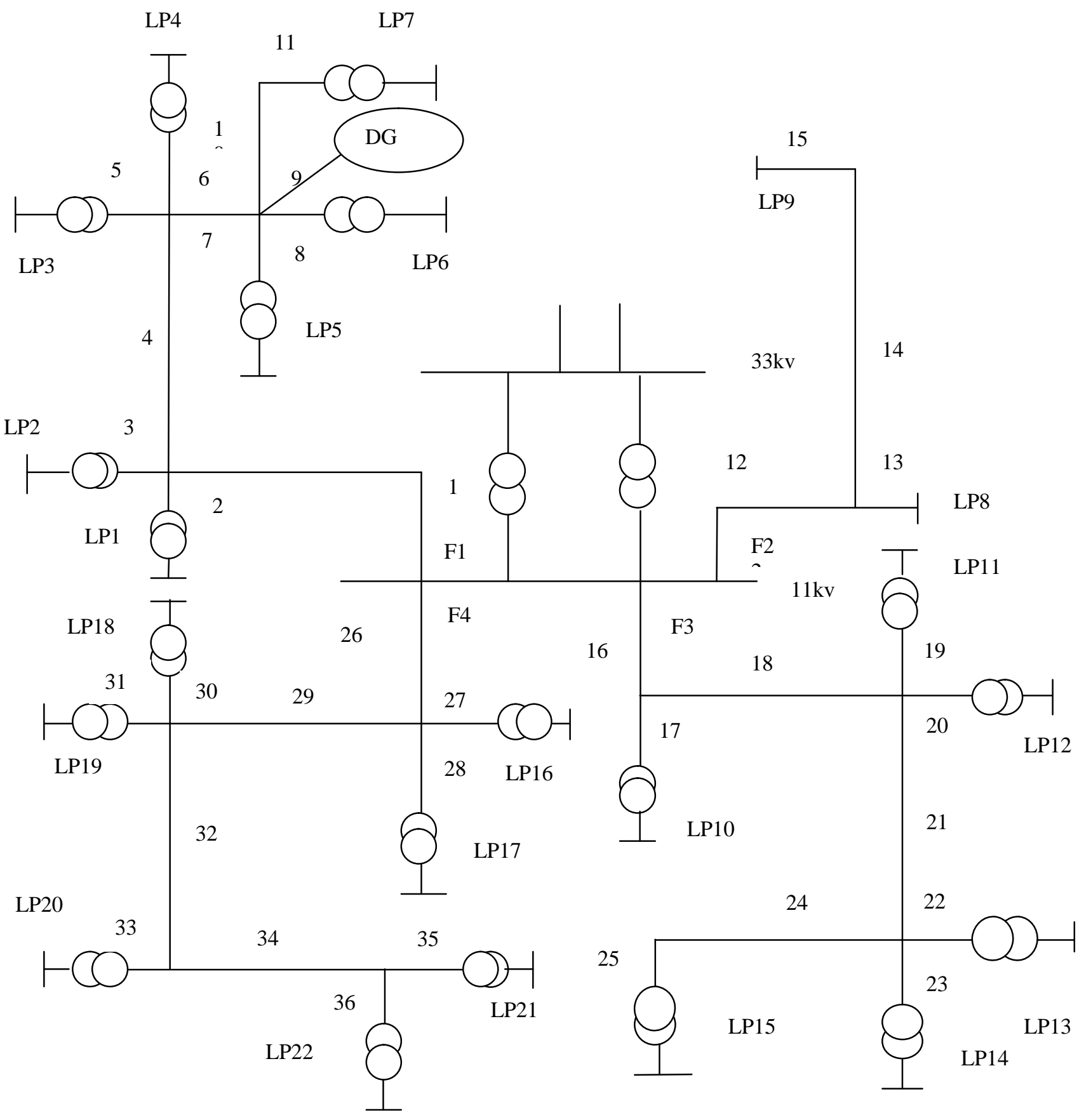

Figure 7: RBTS BUS-2 Distribution Network with DG 
P.Sangeetha et al., International Journal of Emerging Trends in Engineering Research, 9(4), April 2021,491 - 498

\section{RESULTS AND DISCUSSION}

Reliability indices for the RBTS BUS-2 system is compared by using the Analytical and Monte-Carlo methods with and without DG. From the results it is enhanced that reliability of the considered network is improved by integration of DG but for the analytical method it is unrealistic confidence to the user whereas simulation method is over a period of time due to probability distributions.

\begin{tabular}{|l|c|c|c|c|c|c|}
\hline \multirow{2}{*}{ Feeder } & \multicolumn{2}{|c|}{ EENS(MWh/yr) } & \multicolumn{2}{c|}{ ECOST(KRs/yr) } & \multicolumn{2}{c|}{ IEAR(Rs/KWH) } \\
\cline { 2 - 7 } & Analytical(A) & Simulation(S) & Analytical(A) & Simulation(S) & Analytical(A) & Simulation(S) \\
\hline F1 & 2.52 & 2.02 & 7.194 & 8.18 & 3.284 & 4.0495 \\
\hline F2 & 1.12 & 1.117 & 22.302 & 21.02 & 19.91 & 18.8182 \\
\hline F3 & 2.24 & 2.037 & 5.6412 & 5.143 & 2.518 & 2.524 \\
\hline F4 & 2.042 & 2.12 & 6.955 & 6.052 & 3.405 & 2.854 \\
\hline System & 7.922 & 7.294 & 42.0922 & 40.395 & 5.04 & 5.08 \\
\hline
\end{tabular}

Table 2: Comparison for Analytical and Monte-Carlo Method

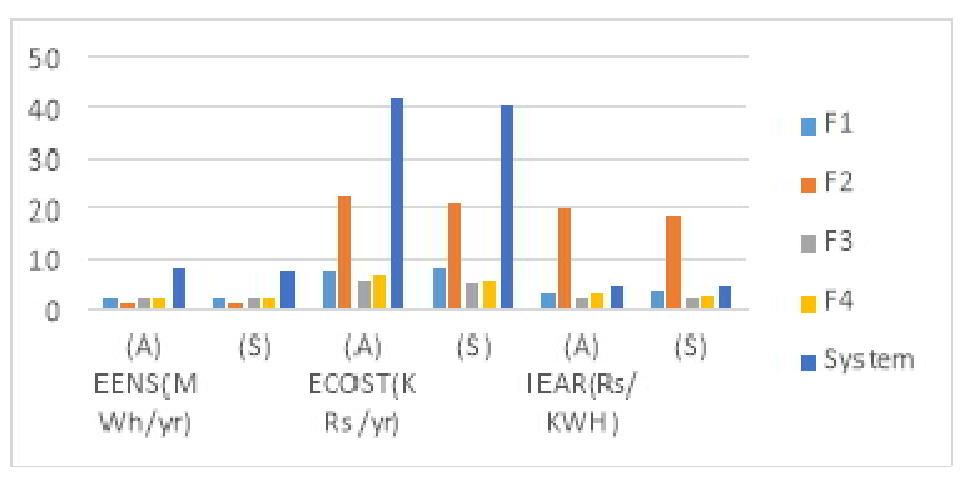

Figure 8: Comparison of Analytical and Simulation for Base System

\begin{tabular}{|c|c|c|c|c|}
\hline Cost/Worth Indices & Feeder-1 & \multicolumn{3}{|c|}{ Total System } \\
\cline { 2 - 5 } & With Out DG & With DG & With Out DG & With DG \\
\hline EENS & 2.52 & 0.89 & 7.922 & 4.85 \\
\hline ECOST & 7.194 & 4.22 & 42.0922 & 35.2 \\
\hline
\end{tabular}

Table 3: Cost/Worth Indices Comparison

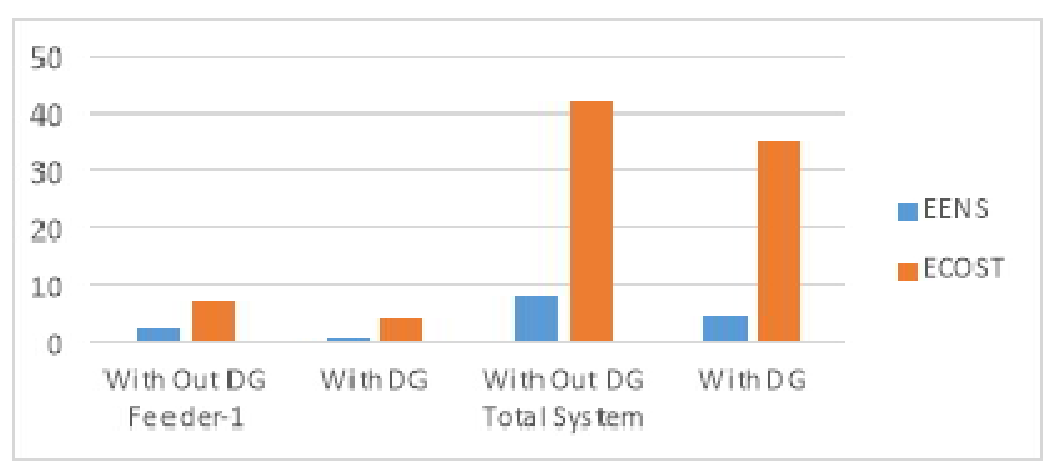

Figure 9: EENS, ECOST with and without DG 


\section{REFERENCES}

1. Billinton R. and Allan R. N. Reliability Evaluation of Power Systems, Plenum Press, New York, 1984, Reprinted in India, BS Publications, (2007).

2. Billinton Roy, Peng Wang, Teaching Distribution System Reliability Evaluation Using Monte Carlo Simulation, IEEE Trans. on Power Systems, Vol. 14, No. 2, May-1999, pp: 397-403.

3. R.Billinton, P. Wang, Distribution System Reliability Cost/Worth Analysis Using Analytical and Sequential Simulation Technique, PE-111-PWRS-11-1997, pp: 1245-1250.

4. Javier Faulin, Angel A. Juan, (Editors), Simulation Methods for reliability and availability of complex systems, Springer series in Reliability Engineering, London, (2012) May.

5. R. Billinton, W. Li, A System State Transition Sampling Method for Composite System Reliability
Evaluation, IEEE Transaction on Power systems, Vol. 8, No. 3, (1993) August, pp.761-771.

6. R. Billinton and R. N. Allan, Reliability Evaluation of Engineering Systems: Concepts and Techniques, Second Edition, Plenum Press, (1992).

7. R. N. Allan, R. Billinton, Sjarrief, L.Geol and K. S. So, A Reliability Test System for Educational Purpose-Basic Distribution System Data and Results, IEEE Trns. on Power Systems Vol. 6, No. 2, (1991) May.

8. R.Billinton, E. Wojczynski, Distribution Variation of Distribution System Reliability Indices, IEEE Trans. on Power Apparatus and systems, PAS-104, 1985, pp: 3152-3160.

9. C. Bhargava, P.S.R.Murty Reliability evaluation of radial distribution system using analytical and time sequential techniques, IEEE India International Conference on Power Electronics (IICPE), (2016). 